\title{
The Secret Place in the Life of the Child
}

\author{
Martinus Jan Langeveld \\ Bilthoven, the Netherlands
}

In the lifeworld of the child there exist hidden places which permit the child the possibility of experiencing in a normal manner access to strange and unfamiliar worlds around him. Where does the child find his as yet indeterminate worlds? Worlds pregnant with the possibilities of new meaningful experiences?

Let us, by way of example, turn to the home life of the child.

\section{The Attic}

Has there ever been a stranger place than the attic as it reveals itself to our spellbound eyes when we climb up through the trap-door or hatch? The attic confronts us with a gaze that comes out of nowhere. Its omnipresent stare is not aimed at us directly, rather it suddenly reveals and observes everything at once. As soon as we (after having shut the door) have descended the stairs or the ladder and find ourselves in our own safe familiar world, then its gaze instantly ceases to encompass us. At that very moment the attic resumes guarding its privacy and ours as well, our own privacy, which we had wanted to conquer through our venture into the attic. Let us climb back into the attic and stay there for awhile. Now suppose someone else (mother or father, perhaps) comes up suddenly to peer through the trap-door. Whoever it is will come from a different world, a different reality, than that of the attic. The head of the newcomer belongs to that of an intruder who disturbs the quiet peace of the attic. The intruder's voice is out of place here. Why? Because the secret place has its own life-the intruder destroys it as if it were a soap bubble. The unknown world of the secret place becomes our property. It has curiously become more trusted and personal than any other part of the house.

The secret of the spell of the attic can be encountered both in the deserted emptiness of the attic as well as in the overcrowded condition of another attic. Sometimes a threatening atmosphere hovers in an attic; the attic becomes weird, foreign, unearthly, secretive. The attic does not seem to belong to the normal atmosphere of the rest of the house-the trusted home. The attic can become completely severed from the house and turn into a ship which crosses many treacherous waters-or a grotto carved into the cliff of a foreboding mountain-an eagle's nest crowning on an unreachable mountain top-a perch from which to watch an unfathomable mystery play. The attic covers the normal living spaces below, and yet it seems to stretch unendingly over prairies and oceans bathed in the light of the setting sun. Thus, the attic separates itself, and frees itself from the house in the guise of an airplane or a ship, and so it takes on the changing dimensions of its new being.

But sometimes the attic is just an available space, a room to be used. One can lay a train track there running through savannas. To be sure the train does not travel without hindrances, but these hindrances are not the familiar hindrances one bumps into in the normal living spaces of everyday objects. This uninhabited world of the attic is full of new significations. Here the train winds its way through a landscape of bundles, boxes, 
suitcases, and baskets. One encounters furniture or objects which once were furniture. In the living room it would always be a table and nothing else; tables and chairs and such exist within the boundaries of meaning set by their use. Now that it has been discarded, this piece of furniture takes on an unending array of identities in the free and undisturbed world of the attic. It offers itself as a tent on the prairies in which the chief of the Sioux crouches and smokes the peace pipe with Old Shatterhand. The most common things acquire new names which in the stillness of the old attic seem to be whispered in our ears. Soon we will actually be using these new names.

Although you might not have expected it, this crowded attic shelters hidden places. There are places to crawl into and hide; there are huts and havens, places of refuge, retreats, sanctuaries, dens, caves, holes, and narrow passes to travel through. Every object assumes a meaning which best fits it and makes it a part of this landscape. Except for that familiar storage cupboard over there which we know as the "apple keeper." This cupboard is a stranger to the scene just because of its definite identity and significance. It shows an inscrutable and even disagreeable face. We don't want to bother with it because it obviously refuses to "play along." We don't expect anything from this cupboard. It will remain merely itself. Just look at it. How it stands there: heavy, dense, unmovable. And because of this immutable familiarity, it forfeits its worth and significance. It is precisely the fixed and "everyday" character of this common cupboard which robs it of any possibilities of expression in a world where every object secures a voice of its own. Let us listen to the language spoken by these things. In listening to this language, we may gain a deeper understanding of the nature of the secret place in the world of the young child.

Can I be sure that behind the curtain these lifeless objects are not gazing at me while crouching and getting ready for an unexpected leap? Let us look behind the ruffled creases of the curtain: There stands a docile stove doing what a good stove seemingly should be doing. However, we only need to lift the curtain and let the stove into the familiar world of our livedin daily activities-the stove may only hesitate a moment. But when he seizes the opportunity to serve as ship cannon or robot, he abdicates the idle usefulness of ordinary appliances. He assumes special meaning and thus becomes an essential aspect of the world in which we live. And yet, this world is not entirely "fulfilled by us." There is something vague and indefinable that seems to force itself upon us. For example, we sense this when behind us the lightly lifted curtain suddenly drops down. We catch our breath and the blood rushes to our head: "Who did that?" The "unperson" of the secret place has stirred himself in space, in the flashing moment of the fleeting instant.

\section{Time}

In the attic time stands still or time flies: It really amounts to the same. But if time has stopped, it is not because it has been blocked by the weary recoil or by the nervous density brought about by anxiety or fear. Time simply has disappeared altogether. And when we find our way back from the attic to the livingroom downstairs, the clock looks at us pokerfaced. Maybe time took a rest; but it is also quite possible that the clock stealthily 
moved his arms forward three whole hours as soon as we had left the room. The time which we lost while dwelling in our secret place, or the time we forgot ( "I forgot the time," we say), has really nothing to do with this clock. We don't lose sight of the time, but it is the clock itself we temporarily forget. The secret place does not know the systematic classification of hours, minutes, and seconds. In the domain of the secret place, time is not being managed nor kept within our sphere of control. Somehow, the secret place knows how to remain outside of the boundaries of time and of space. Neither time nor space have room for the indeterminacy of the secret place. And therefore, this is truly a place of secrecy even though it lies there openly for all to see. And so the child finds here a condition for which he would only feel ashamed at school - a state of aimless daydreaming which knows no discipline of time.

\section{One is Lonely Only in the World}

The lonely person who visits the attic learns from experience that the unwavering look of this realm of the indeterminate makes his stay unwelcome. Often the lonely person has come here to overcome his loneliness. He places himself amidst the used furniture and the old suitcases, which, through their own superficiality and worthlessness, have become redundant, silly, powerless, and yes, even lifeless. Dead to the dead. This is how he sees himself in the midst of these objects. But even if the lonely person is misplaced here, still the normal child is glad to be alone in the attic. Company is only thinkable in the experience of a commonly felt joy. This commonly held enjoyment of the secret intimacy of aloneness can be experienced in many different places: for example, in bed, in a quiet evening at home, during a hike in the wilderness, or in the simultaneously exchanged glance with a beloved pet, etc. In the attic the mundanity of the quarrels, irritations, and conflicts of daily living fall away from us because here we are asked to create our own world, a world we live through as an indulgent illusion. Above all, it must not be merely-disguised illusion, an illusion in which one partakes with bad conscience. Whoever wants to live in the secret place but hesitates to give himself over to the sense of illusion it requires has already forsaken the place before he has even entered it. $\mathrm{He}$ has been driven into the straits and must realize that he has lost his freedom. He wastes his time here. He is displeased with himself and feels himself frustrated. He is ashamed of his childishness. He will soon feel lonely if he is not already lonely. But whoever truly enters the secret place, enters a true illusion. The reality of the world he himself has created is experienced with an honesty of immediacy. And yet, like the dawning of the morning glory, there is a dawning awareness of the personal quality of this new world and a personal familiarity with it; at the same time, the road to the normal world of shared relations remains familiar and open. But the secret place knows no bad conscience. Here we live in a true state of innocence.

The secret place is, then, a home where one finds oneself at home, a place where one is with oneself. Its intimate character is determined, in the first place, by the fact that one finds oneself in the unexpected presence of one's own self without having tried to make oneself a project of study. Here, one has every opportunity by doing or dreaming to realize, to make 
real, a world of one's own. Nothing interferes with the multiplicity of relations the objects of this world have to "reality." This box can be a box, but it can also be a cave which surrounds me, or a fortress, a cliff, a boat, an airplane, or a building block. I myself can be an explorer, a pirate, a pilot, or a scientist.

At the same time, to spend time in the attic means still to be at home. For there is still the stairway. There one can still climb down. But the stairway has its own significance as well. And this significance becomes stronger when we look up the stairway towards where it leads into the unknown or to the unseen. In case we cannot remember this feeling, we should consult the etching by Odilon Redon in which a stairway is shown in a hallway. In the background to the left one sees the reverse side of the stairs. This room has an air of uncertainty about it precisely because of the presence of the stairway which leads up to the unknown and to the invisible. There dwells the anonymous being, the unperson. Watch out! Soon he will peek over the ramps and look at us.

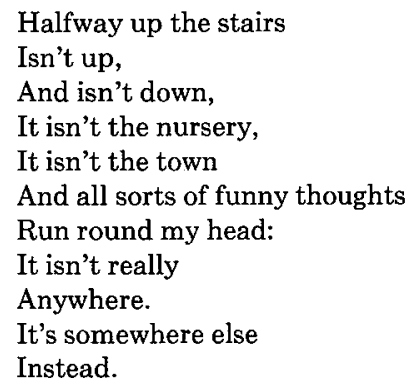

(Milne, "When We Were Very Young")

Indeterminate space, indeed, that is what the stairs represent because we cannot see where they lead. Of course, the staircase can be very familiar and trusted with the exception of those which lead up to the attic since these always contain an element of mystery. For the attic is the indeterminate space itself. Sometimes the staircase looks at us through the eyes of a distant piece of furniture, visible from below and which, in spite of its distance, gives us a feeling of trustfulness. At other times the staircase is a dark and threatening space precisely because of the peculiar way it is kept bounded by the over-arching roof; yet the unbounded dome of a dark or starlit sky tends to create no fear in us at all. At other times we may have the feeling that the stairs lead into nothingness. The Jacob's-ladder, and the ladders without end are familiar dream themes.

Sometimes children have found their secret place in a deep closet. One barely opens the door to see a gaping, dark space, whose emptiness strengthens the sense of indeterminancy. This indeterminacy is not to be equated with meaninglessness. Emptiness is a space which speaks to us to be filled, or it can invite us to explore its cavities and corners. Moreover, the empty space is the dwelling place for occasional visions and strange creatures or appearances: what is empty at one moment suddenly shows an invisible life. In fairy tales there were always princes and fairies who suddenly became visible. And then there are the shuddering experiences of Edgar Allen Poe such as when we hear knocking from a closet which we 
thought was empty. But this is not what we are referring to here. For that experience no longer belongs to the hidden place in the life of the childinstead it would truly be a threat.

The full utility closet certainly loses its significance as a secret hiding place. For it is simply one of those ordinarily useful cupboards. At best one can only hope to find an unexpected object there. This search for something worthwhile in the inside of a full cupboard or closet bears no relation to the experience of the secret place. For here there is nothing indeterminate; everything belongs to someone. Here there is no mystery, no drawing back of oneself from the objective time and space boundaries. Here there is no seeing of oneself as the "other." Even the shallow closet is a purely useful object, completely without mystery, without practical freedom.

In contrast, the lookout post from a tower, or a tree, or from the roof, or from any such kind of place is for many a child a retreat from the nearness of things. The things to which we direct our attention from a lookout post are always far away. It could even be something from which we are normally barred or locked out. That is how it is for Piers Sparkenbroke in Sparkenbroke by Charles Morgan. The twelve-year-old hero retreats to his observation post so that he can follow the annual festival pilgrimage to the family burial grounds. He was not allowed to go along because he was considered still "too small!" Now he finds five windows covered with heavy curtains. "He pushed two of the curtains to the side, slid inside and let them fall shut behind him." Now he stands in an empty room, cloaked in darkness where only the sound of the church bell enters. This clear sound only heightens his feelings of being shut out, but at the same time it increases his pride which he, Piers, discovers in his search for an encounter with death. He knows, of course, of the fear and anxiety with which the others approach the trip to the grave. For Piers the bells do not signify fright, but rather revelation. He is beguiled by their incomprehensible novelty, which (if only he could distinguish them) could fulfill his consciousness of that other life, that out-of-body life, of which he already knew more than a little. Outside of the realm of time, which is seen as if it were a measuring tape which, unravels, hour after hour, like a kitchen clock, Piers encounters a mode of being totally unexplored by man. The world which he observes while in hiding is the world of isolated and separated secrets. One knows what is "actually" going on there. One looks, as it were, unnoticed over the shoulder of the worker and follows with one's eyes the impulses which flow into the world through his hands and his expressions. In this secret place, then, two experiences come together: that of being the outsider at a distance, and that of having understood a reality. The experience of the outsider, the onlooker, and that of the initiated, the knower, are here united. And that is why, without participating in what is happening, we can be happy in that place.

Piers was unable to give expression to his experiences, and yet he could not help but show in his very way of being and behaving that the experiences were somehow consequential. He could no longer deny that he had encountered the indeterminate mode of being. And although it may be true that Piers was an extraordinarily sensitive boy, in some deep sense 
every child has knowledge of some such experiential encounters with a secret place, even though it may not always be in the same manner.

Piers stood behind the curtains of a familiar and trusted room in his house. When these curtains are drawn, they close in the familiar world; when they are open, they provide a view to the world outside. But whoever stands behind the curtains next to the windows stands in no-man's land, as it were. This is a land which belongs neither to the living room inside, nor to the world outside the window. Here we are dealing with a narrow, intercontinental strip. Here we are at home, in the real and immediate vicinity of the others, so that really nobody needs to notice our absence. "But look, I have been right here!" answers the child after we have been searching for him all over the house. "I was here, in the room!" But to himself he might say: "Indeed, I was here, and yet..."

\section{The Place Becomes Determinacy}

The secret place changes with age. The three year old, crouched in the corner with his back to the others, has as yet no secret place. The four or five year old discovers by accident the stirrings of the secret place behind a piece of furniture whenever he may feel sanctuary there, but he will make sure that he is still connected to the familiar, normal world.

Sitting under the table is such an experience. It is pleasant and cosy there. Not too dark. You can see the shadows on the walls, and here are the feet of mother or father. You can hear especially well what is being said. This kind of place does not force the child yet to encounter the availability, the emptiness, and his ultimate creative responsibility. So the child still tends to look outward: that is, to continue to talk with others and to keep an open eye for his interests out there. But at eight years of age the child begins to create his own world-between the fence and the bushes, behind the garden fence, and in the ditches. These are "secure" places, and so he plays games quite openly. The shed and the workshop belong there toothese rooms serve the interests of the practical and the necessary, and yet a different "spirit" reigns here as well. Here one has escaped out of the world of grown-ups in which one is only "just" a child. Here one is free from this world, and now one can create totally useless and wonderful and fascinating things out of odds, ends, and pieces. Here one may gain a glimpse already into the mysterious world of the secret place.

First Santa Claus dies. Children over eight can hardly accept him anymore in real life. Increasingly, make-believe and legend gain favor in the world of adventure created by the child himself. Life or adventure stories take the place of fairy tales. The child is no longer dependent on the completed pictures offered him. And that which one has called the age of the "reality-fanatic" is, much more accurately, the age of fantasy, discovery, and the production of personal creativity. The attic, now transformed into wooded and forested fields, becomes a new play area. Such places are full of dynamic and expansive characters-Indians, cowboys, cavalry, and robbers. Now the most significant period of the secret, mysterious places begins. After a time, when the business of shaping the world and the self stops being a free and carefree past time, then the secret place becomes childish, and the child descends from the 
attic into his "own room." But the "own room" of the adolescent remains a very personal space. The child's need for creating a personal form finds its expression by means of secret diaries, poems, and true friends. Emptiness and darkness do become motifs in the life of the older child, but now they no longer say, "Stay." The child is already a more social being and spends more of his time with grandiose and deep thoughts. He may now even begin to think about planning his own life. And his own room becomes the possibility and precondition for creating a personal life. More and more the child will experience preference for a certain and determined place. Having been a vagabond for some time, he now develops into a youth who is looking for "his" place. During the change from youth to adult, this search loses its diffuse "serious play" character, and one slides into situations which belong to the social and adult world. Now one inhabits neither one's secret place nor one's own room; now one lives at home and works at one's job.

For the young girl, her own room may become more and more a living place, an intimate milieu, and there may already be a concern about the creation of one's own home life. For the boy, in the second half of his youth, his room becomes a garrison, or his own workplace. The adult too knows the notion of one's own dwelling, one's own home-our house, our room, our shop. Primitive man had his hut, and as long as we do not have a hotel or a room which can become home, we do not feel right in a strange country. From there we begin. This room, this native hut in the wilderness, is intimately tied up with our person-hood. This home will also become our place, full of us, reflecting who we are, made by us, as, in an earlier time, it was the case with our hut, our attic, our room.

\section{Body and Space}

In other areas, too, we find that the child pursues his original childhood or, better, that aspect of his youth which is not affected by school. This is typically visible in the way that the child experiences his body and its relationship to space. We want to watch the child in this area so that we can clearly see the contrast with school experience and therefore the specific contribution of schooling to the growth of the child. We need only remind ourselves how strongly the classrooms of the school are determined by interests of exactness and objectivity in order to ask whether the child's experiences differ from this. We also know how the school dictates the bodily behaviour of the child according to unyielding codes and policies. But how does the child experience his body when he is allowed to live it in his own subjective world?

In my lived space the phenomena present themselves to me, and the space is simultaneously the place where I can move and dwell. It is also the world in which the eidetic image, the sensory illusions, the dream images, appear; here, too, the centaur appears, the calling voice, and the approaching car. It is the world in which the stone we throw flies upward and falls downward again, in which I am either rash or timid, in which I can take the way home and the way to the centaur.

At the center of our space there is something of which the spatial character is of secondary significance: the body, our corporeal self. Its 
visibility is therefore so much more important. The body is an "object" in visual space. At the same time "my" body is known to me for the claims it makes on me; I am hungry, have a toothache, my hand itches, I admire my well manicured fingernails. It is a fact that we are dealing here with $m y$ body which is growing and recording my personal history. And yet, I "find" my own body, or encounter it in space only under specific and often not favorable circumstances. The disturbing alienation of his own body which the child experiences at the time of puberty is no less conspicuous than that found by the psycho-pathologist in his practice. Sometimes a child falling asleep in a darkened room can frighten himself with the appearance and movement of his own hands. Here, then, we are dealing with the encounter of one's own body as an object. This is something quite different from "knowing" one's body and its peculiarities, that is, having knowledge about one's body.

What interests us here is "my body" in as much as it is that through which I can shape the space of my world - the path I am walking along, the space which I create, in which I wander, dance, or stagger towards an unreachable resting place. We are dealing here with a being who lives corporeally, not like an angel, a dwarf, or the spirit of light which is everywhere and nowhere present and which could inhabit any space. However, this corporeal being perpetually escapes its body and thus creates its space. It finds itself there where the ball will shoot over its goal. It is there where the victim will fall, there where he himself will soon be. Since Sartre, one has seen all this explored under several categories. But this body which I ordinarily pass over has also been given to me so that I can help it to meet its aims, and so that I can reach a goal. And then I may experience it as slow, tired, too hot, aroused, or stirred up, etc. In this manner the child is put emphatically in touch with his body: he cannot reach every goal because he is "too small"; he cannot keep step with adults because his legs are too short; he cannot carry a suitcase because he is not strong enough; he works clumsily because his hands are too small and too weak. But parallel with this experience is the positive experience of the self-assured, supple and moveable body which grips and reaches. Of course, the child is naturally inclined to grabbing and reaching, and in this way he steps into the world of the reachable and "grabable," but this being directed towards is not thinkable without an "I" which reaches and grabs. And so it is this "I" who stretches out the hand and reaches, or does not reach that which it wants, who is therefore experienced as too small or too weak or not fast enough.

The body, then, is never completely shut out. The body is both the challenge of the jump and the jumper. The child shows this in childlike fashion. But the adult who sees how a child walks, climbs, slides, dances, jumps around, runs, rolls, and bounces, perceives these actions in the context of what he believes to be a shared space. He runs and jumps in the same space as the child. The adult concerns himself with the jumping as if it were simply an altogether proper and normal thing for people, animals, and even things to do. And he is convinced that this occurs in the same space in which one finds this vase, or in which that siren howls, or the doorbell rings. But such normal adult assumption is only minimally correct: He classifies activities according to rules which shut out that 
which moves itself. That is exactly the opposite of what a psychologist should do.

The teacher, too, believes himself to be in the same space, this "room," as the child. He is wrong for the child lives this "room" in his own reality. Thus, the large classroom can really be quite small for a child if he is frightened or feels trapped. The same room, however, becomes quite big when one is chasing around in it. Even here the physical aspects mislead us adults for they can be experienced differently by children and by adults. However, school proceeds on the basis of a common perception, and in this it brings the child to learn to conform to whatever is considered normal. If we do not want to keep the child infantile, then he must go through some patterns of development, and it is our job to lead him through it.

Undoubtedly Froebel had a clue in this matter. But he hid his clue in a theory which could not benefit the psychological research of the child. On the one hand, the theory puts forward the notion of "acting-space," but, on the other hand, Froebel remains true to the mathematical idea of spacethe empty shell which sometimes becomes embodied as a "thing," for example, as a round ball, a pail, or a tub.

But space is something that "happens"; it "overwhelms" the child. The child gains a hold of it when the experience of perspective is encountered, when one goes "behind" something which, like a piece of stage scenery, represented, until now, the end of the world; or when one goes "around the corner," by changing direction in order to avoid an obstacle. The child masters space through other discoveries as well: some obstacles he may not be able to get around, but he is able to get over them.

The particular aspects of so-called "objective" space, for example, its three-dimensionality, are, psychologically speaking, secondarily perceived. Primary is the fact that we can move ourselves, spread about, reach toward, walk through, see and hear what is somewhere over there. The corporeal existence of the child must be understood here in essentially anthropological categories: the body is no stone or tree. It is my own manner of being for the world and in the world. My corporeal existence in the world also shows itself in that the moveable parts of my body-my eyes, hands, feet, fingers-seem to be drawn as it were by the things or objects of the world. This is true already for the very young child: he sees something, stares at it, and tries to grab it. As we get a bit older, we become more mobile and go to the things by ourselves. We crawl to the chairs, under and around them. We climb on them, fall of them, and walk around them. "That is so because they are three-dimensional!" No! On the contrary! They are "three-dimensional" because we can sit on them, etc.

The lived experiencing of space is dynamic; space is "created" personally. The chair loses its peculiarity as a place under which one sits as soon as other bodily proportions begin to make sense of the space. The "big" objects become "small," what used to tower over me is now my height, that which was distant draws nearer, what was hidden becomes visible and reachable. The skipping child shapes his world differently from the child who is simply walking, or the one who jumps over the fence in one motion. The world of the hopping child structures itself jumpingly; these jumps are guided by the patterns of the ground or the drawings on the streets: it goes 
from one side to the other, and the direction of movement is determined by the shape of these patterns. The child that moves forward in this way, hops through a space which shrinks to the short distance that one can cover in one leap. By simply lifting one foot and hopping, the small child finds gratification already in the hopscotch play, even if he cannot move from his place as yet; the shape of the space, which he will jumpingly explore, has begun to form itself already.

The child who is involved in games such as sack races or running a distance while balancing an egg on a spoon has the same experience. For the former, the distance grows immeasurably far as soon as his legs are caught in the sack. For the latter, the way ahead becomes unbearably bumpy and seems to resemble a trip. On all sides he is surrounded by a crowded and threatening space. He runs a gauntlet while attempting not to bump against the surrounding air and letting the egg fall- "Hey you, don't bump me!" "What do you mean? I wasn't even close to you!"

When the boy Kees, in the familiar Dutch novel by Theo Thyssen, puts on his running shoes, he becomes a famous gymnast and he flies through space like a long-distance runner. "What misfortune has prevented him from achieving fame? It could not have been his fault." Such a child creates a personal world, in which intentions, motion, and space complement each other. Such things actually happen in a gymnasium-one need only look for them.

We have already mentioned that the proportions of the child's body change continually; especially during the period which begins in the tenth year, and then during puberty one encounters sensations like those of Alice in Wonderland. Everything becomes "curiouser and curiouser." The whole body grows unendingly. "It unfolds and opens like the biggest telescope. Goodbye, dear feet." As she watched her feet, they retreated from her at "such a rate that she lost sight of them." This is how Alice lived the experience of discovering her own growth.

And so the child of this age is a tireless wanderer who becomes a hiker and a vagabond. For the one as for the other, the horizon stretches further and further ahead. First there is the feeling of untiring bodily energy, and later the unsatisfiable yearning for some other far place. The body and its movements create a world in which this life unfolds, in which "I live."

From a psychological point of view it makes no sense to emphasize the "three-dimensionality" of the child's space. This space takes on a personal shape of the environment: in this secret and hidden place under the table, behind the curtain, in the attic. Space also arises out of the personal shaping of movement-in the school yard, place and movement call each other forth.

In adults the need for an appreciation of a private place, a space which assumes personal meaning, never disappears because this need is inseparably connected with the essential personality of humanness. However, it is no longer a "secret" place: that is, a place without destination which has not acquired fixed meaning and in which the world is still free, unformed, and indeterminate. Now it has become the place where we live with our family, with loved ones; this is our home, our studio, and our 
neighborhood pub where we are patrons. In case of emergency, this place can become a refuge or a place of adventure. A person does not withdraw to the "secret, quiet, mysterious" place for hatching wicked schemes. Rather, he comes there to be with himself and to give his dreams and his senses free rein. In the "secret" place one can surely experiment with fantasies, like in the closet of Cagliostro. If a misfortune happens to occur there, then it was not a planned one-it just happened by accident. If a child withdraws in order to contemplate some evil, then it is not to his secret place, but rather to the place that is merely hidden from others and must remain that way so that evil can be prepared. The secret place is the world of guileless good will, the place where the subject innocently reshapes himself and his world. So it is not the world of an adult, whose life consists of fulfilling tasks and duties, who holds notions of himself as having the creative duty of the artist and the childrearing duty of parents. It is also not a place for the "elder" whose personality has already taken on a grain-finished form, nor for one in whose life there is no place for creative activity of the individual "I." We have referred to that aspect of the world which has no fixed determinant meaning as the "secret place," and we have seen that this lived space has the pedagogic significance of a task, a necessary part of growing up in our personal life history. Therefore, the school, too, must have a fundamental understanding of this indeterminate place and must not fall into the mistake of viewing the whole world as school. Many things must be learned outside of the school-world. And although so much must be learned, it does not follow that we must teach it all.

\section{Notes}

1. This is the second part of Langeveld's phenomenological description of the secret place in the life of the child. The first part was published in Vol. 1, No. 1 of this journal. The article has been translated by Max van Manen.

2. From M. J. Langeveld, Scholen Maken Mensen (Purmerend: J. Muusses, 1967). 